\title{
Moral e Ética: Uma Leitura Psicológica
}

\author{
Yves de La Taille ${ }^{1}$ \\ Universidade de São Paulo
}

\begin{abstract}
RESUMO - Após um século de reflexões e investigações, como era de se esperar, a Psicologia Moral apresenta sinais de esgotamento de seus referenciais teóricos clássicos. Consequentemente, novas perspectivas se abrem, entre elas a abordagem teórica que leva o nome de 'personalidade ética', cuja tese é: para compreendermos os comportamentos morais (deveres) dos indivíduos, precisamos conhecer a perspectiva ética (vida boa) adotadas por eles. Entre os invariantes psicológicos de realização de uma 'vida boa', está a necessidade de 'expansão de si próprio'. Como tal expansão implica ter 'representações de si' de valor positivo, entre elas poderão estar aquelas relacionadas à moral. Se estiverem, o sujeito experimentará o sentimento de dever, do contrário, a motivação para a ação moral será inexistente ou fraca.
\end{abstract}

Palavras-chave: Psicologia Moral; moral; ética; personalidade ética; representações de si.

\section{Moral and Ethic: A Psychological Reading}

\begin{abstract}
After nearly a century of reflections and investigations, as it would be expected, the classical theoretical referentials of Moral Psychology show signs of exhaustion. Consequently, new perspectives open up, including the theoretical approach that takes the name of 'ethic personality', whose thesis is: to understand the moral behavior (duties) of individuals, one needs to know the ethical perspective (good life) adopted by them. Among the psychological invariants to hold a 'good life' is the need for 'expansion of the self'. Such expansion involves positive 'self representations', among of which may be those related to morality. If so, the subject will experience the feeling of duty, otherwise, the motivation for moral action will be weak or non-existent.
\end{abstract}

Keywords: Moral Psychology; morality; ethics; ethical personality; self's representations.

No começo do século XX, em 1902 exatamente, LévyBruhl, para quem "uma moral, mesmo quando quer ser teórica, é sempre normativa, e, justamente porque é normativa, nunca é realmente teórica" (1971, p. 12), propunha que a moralidade fosse finalmente tema de investigações científicas, notadamente psicológicas. O seu conselho foi seguido e, assim como na Filosofia, praticamente todos os grandes autores na área da Psicologia se debruçaram sobre o tema da moral. Os construtores de grandes 'teorias do sujeito', como Freud, Piaget e Skinner, para citar apenas três, dedicaram-se a pensar a moralidade por intermédio de suas respectivas abordagens teóricas. Todavia, os três autores citados o fizeram de maneira, por assim dizer, ocasional. Com efeito, a moral não é o tema central da psicanálise, nem o é do construtivismo piagetiano, e tampouco do behaviorismo skinneriano. Seria preciso esperar a segunda metade do século passado para que a chamada Psicologia Moral se tornasse campo preciso e consagrado de estudo, notadamente graças às já clássicas contribuições de Lawrence Kohlberg. Como o psicólogo americano inspirou-se no livro pioneiro de Jean Piaget, Le jugement moral chez l'enfant, publicado pela primeira vez em 1932, pode-se dizer que a linha mestra que orientou grande quantidade de estudos e pesquisas foi tributária das ideias do criador da Epistemologia Genética. Note-se que, no Brasil, a área da Psicologia Moral foi desen-

1 Endereço para correspondência: Via das Acácias, 731. Jardim Colibri. Embu, SP. CEP 06805330.E.mail: ytaille@usp.br. volvida por vários pesquisadores, como o atesta a existência, desde o início da década de 1990, de um grupo de trabalho da Associação Nacional de Pesquisa em Psicologia (ANPEPP) dedicado ao tema.

No final do século XX, assiste-se, como era de se esperar, a certo esgotamento do referido modelo teórico, que costuma responder pelo nome de construtivismo, não que ele se mostrasse 'errado' (tantos dados comprovaram sua relevância), mas porque não somente não oferecia grandes perspectivas de novos e relevantes achados empíricos e teóricos, como, centrado no aspecto racional da moralidade, relegava a uma zona obscura os motivos humanos da ação moral (que não se reduz ao juízo moral, embora dele indissociável). Novas perspectivas, então, foram encetadas.

Como o presente texto não se pretende 'didático', logo não pretende contar a história passada e recente da Psicologia Moral, nele será tratada uma dessas novas perspectivas por intermédio de conceitos e propostas teóricas que foram elaboradas durante a década de 1990 e os 10 primeiros anos do presente século.

A tese psicológica que vamos aqui analisar pode ser assim enunciada: para compreendermos os comportamentos morais dos individuos precisamos conhecer a perspectiva ética que estes adotam.

Tal afirmação, é claro, pressupõe uma diferença de sentido entre os conceitos de moral e de ética. Vamos, portanto, começar por explicitar a diferença de sentido assumida para, em seguida, nos debruçarmos sobre a tese acima apresentada. 


\section{O Plano Moral}

A Psicologia trabalha com fatos. Vamos, então, nos perguntar se a definição que Kant (1994) propõe da moral corresponde a uma possível realidade psíquica. Como se sabe, para o filósofo de Königsberg, somente é moral a ação inspirada por um imperativo categórico, portanto, oriunda de um dever incondicional. Logo, para Kant, a moral ordena: o sujeito moral sente-se intimamente obrigado a agir segundo determinadas regras. Sua ação é, para ele, necessária, e não apenas possível ou provável, e isto porque o bem moral é um bem em si. Não nos interessa, por enquanto, discutir o conteúdo da moral assim definida. O que nos interessa é saber se, sim ou não, tal sentimento de obrigatoriedade corresponde a um fato psicológico, pelo menos em alguns indivíduos. Se a resposta for afirmativa, seremos obrigados a reconhecer que existe um plano moral possível na psique humana (empregamos o conceito de plano moral para separar forma de conteúdo: tal plano é o lugar do sentimento de obrigatoriedade, seja qual for a regra contemplada - a moral é sempre uma determinada moral, portanto, comprometida com determinados valores, princípios e regras).

Ora, a resposta à nossa pergunta certamente é afirmativa. É, pelo menos, o que a experiência leva a pensar, e é também o que autores dedicados ao tema que nos interessa assumem. Vejamos alguns exemplos, começando por dois filósofos.

Tugendhat (1998), ao perguntar-se que critérios intervêm para que um juízo seja concebido como moral, analisa os sentidos das palavras 'bom' e 'dever'. Eis a sua conclusão: "Todas as proposições que comportam - seja de maneira explícita ou implícita - a expressão gramaticalmente absoluta de um dever prático ou de um valor ('bom' ou 'mau') expressam, nesse sentido, juízos morais" (p. 31). A referência ao absoluto, que se encontra nas falas usuais dos indivíduos, corresponde ao que estamos chamando de plano moral, e a linguagem expressa a existência psicológica de tal plano. Dupréel (1967), pesquisador de formação filosófica e que se propôs a escrever um Traité de Morale, no qual analisa as dimensões sociológicas e psicológicas da moral, também vê na definição kantiana um aspecto incontornável da realidade psicológica. Escreve ele: "O puro respeito pela regra, eis o fato decisivo; e por pouco frequente ou limitado que seja este estado de consciência, é isto que importa à ciência explicar" (p. 164).

Na área da Sociologia, Durkheim (1974), preocupado em demonstrar a viabilidade de uma educação moral laica, aceita a definição de Kant, que ele traduz por "agir bem é obedecer bem" (p. 21), e encontra no sentimento do sagrado a explicação psicológica da existência do sentimento de obrigatoriedade. Para o sociólogo francês, o plano moral corresponde a uma realidade humana, realidade esta durante séculos despertada pela religião, mas também passível de ser ocupada pelos mandamentos do Ser Coletivo.

Na área da Psicologia, Freud (1991) não hesitou em afirmar que o superego "se manifesta enquanto imperativo categórico" (p. 278). Sabe-se que a força superegóica tem, para Freud, sua origem em esferas inconscientes: logo, sua referência à terminologia kantiana não o compromete com a existência de um 'tribunal da razão', para empregar uma feliz expressão de Deleuze (2004). Mas que há um 'tribunal', há - aliás tão implacável quanto aquele imaginado por Kant - e cabe à Psicologia explicar o lugar e a origem dessa voz da consciência que coage o homem a agir de determinadas formas, e não de outras. Mais perto da hipótese de um tribunal da razão está Piaget (1932), para quem a moral da cooperação implica a presença de um sentimento incontornável de dever. Para ele, "tal tese só é chocante para os que permanecem incapazes de experimentar em si próprios esta obrigação superior e puramente imanente que constitui a necessidade racional" (p. 298).

Em suma, é perfeitamente legítimo afirmar a existência de um sentimento de obrigatoriedade, e explicar tal existência é um desafio para a Psicologia. Antes de passarmos a refletir sobre os possíveis conteúdos desse plano moral e as fontes energéticas de sua força psicológica, façamos dois comentários.

O primeiro: o sentimento de obrigatoriedade (ou dever) experimentado por um sujeito não corresponde sempre e necessariamente a uma exigibilidade social. Essa correspondência pode acontecer: por exemplo, quando alguém pauta suas ações pela regra 'não matar' e vive numa sociedade na qual o matar é moralmente proibido. Há, por assim dizer, uma dupla exigência: uma pessoal (o imperativo categórico) e outra social (castiga-se e/ou se despreza o assassino). Porém, tal correspondência pode não existir, como no caso de uma pessoa para a qual ser caridoso traduz um dever, mesmo vivendo numa sociedade na qual não há regra que vise obrigar a todos fazerem 'dom de si'. Em geral, a obediência às regras que dizem respeito à justiça costuma ser socialmente exigida, enquanto a obediência àquelas que tratam de benevolência, não. Mas o que importa sublinhar aqui é que o sentimento de obrigatoriedade poder ser experimentado sem que haja exigibilidade social do comportamento decorrente.

O segundo comentário incide sobre a frequência, na população e no próprio indivíduo, do referido sentimento. Comecemos pelo aspecto populacional: a maioria dos homens sente-se movida por essa força interna chamada dever? Ou são poucos aqueles que experimentam tal 'obrigação superior'? É evidentemente impossível responder estatisticamente a essa indagação, mas o bom senso costuma fazer com que nos inclinemos pela raridade do fenômeno. Daí, aliás, a admiração comumente despertada pelas pessoas capazes de sacrifícios em nome de ideais morais. Os estudiosos da moralidade também costumam mostrar-se prudentes na hora de generalizar a um grande número de indivíduos a capacidade de serem inspirados por deveres. A citação de Dupréel (1967), transcrita acima, o atesta claramente. Freud (1971) também expressa seu pessimismo moral dizendo que em numerosos adultos, o medo da punição, e não o sentimento do dever, explica a correção de seus atos. Assim, escreve ele, "esses adultos permitem-se cometer um mal suscetível de lhes proporcionar prazer somente com a garantia de que a autoridade nunca de nada saberá ou nada poderá lhes fazer; apenas o medo de serem descobertos determina sua angústia" (p. 81). O próprio Piaget (1977), certamente mais confiante nas virtudes da humanidade do que seu colega psicanalista, admite que a enorme coerção exercida pela sociedade no que tange aos termas morais impede que a maioria aceda à autonomia moral. Ora, em fase de heteronomia, segundo ele, o sentimento do dever ainda é fraco, pois exterior à cons- 
ciência. Assim, vemos que Dupréel, Freud e Piaget pensam ser rara a determinação das ações humanas por imperativos categóricos. Lipovetsky (1992) tem a mesma opinião, mas por motivos de ordem cultural. Segundo ele, vivemos tempos de crepúsculo do dever, nos quais "cessamos de reconhecer a obrigação de nos apegar a outra coisa que não seja nós mesmos" (p. 15). A rarefação do sentimento de obrigatoriedade não seria devida, portanto, a fraquezas de caráter que, em todas as épocas, minam a força moral da maioria dos homens, mas sim a uma nova ordem social individualista que mais valoriza o prazer que o dever. A sociedade pós-moderna seria também a sociedade pós-moralista. O livro de Lipovetsky é instigante, repleto de exemplos e análises importantes, todavia, não pensamos que as ciências humanas possam alegremente abandonar o tema da moralidade, nem que seja porque muitos contemporâneos sentem os efeitos do suposto pós-moralismo como dolorosos e inquietantes para o futuro da sociedade ocidental. Huntington (1999), em seu polêmico livro sobre o 'choque das civilizações' atesta tal mal-estar.

Raro? Talvez. Em franca regressão? Talvez. Resta que o sentimento de obrigatoriedade é tema humano incontornável.

Mais interessante do que indagarmos sobre a frequência do sentimento de obrigatoriedade entre os seres humanos é nos perguntarmos sobre essa mesma frequência em cada indivíduo. O herói moral, o santo, é aquela pessoa cuja voz da consciência sempre fala mais alto do que as outras. Ela desconhece fraquezas que a fariam desviar-se do claro caminho do dever. Esta é a exceção, não a regra. O mais comum é o homem 'cair em tentação', como se diz no âmbito cristão, às vezes tornar-se surdo à voz de sua consciência moral. Longe de comprometer a validade do tema que nos ocupa, tal fenômeno o torna ainda mais interessante, pois ele nos mostra que devemos pensá-lo no âmbito do conflito pessoal. Em algum lugar, Wallon disse que os 'eclipses' permitem melhor estudar os fenômenos momentaneamente invisíveis. $O$ fato de às vezes acontecerem 'eclipses' do sentimento de dever pode nos ajudar a melhor compreender as dimensões psicológicas que o tornam possível. Voltaremos a elas.

Para finalizarmos nossa análise do plano moral, faltanos perguntar se tal plano implica determinados conteúdos (uma determinada moral) e que fontes energéticas alimentam o sentimento do dever. Interessantemente, essas duas questões, na verdade distintas, mostram-se relacionadas nas teorias psicológicas. Encontramos o seguinte: as teorias que identificam uma fonte energética para o dever apontam para uma relativização do conteúdo da moral, e as teorias que postulam que uma determinada moral tende a imporse à consciência deixam em aberto a dimensão energética. Durkheim e Freud são representantes das primeiras; Piaget e Kohlberg, das segundas. Vejamos como esse quadro se apresenta, começando por pensar a questão do conteúdo que pode ocupar o plano moral.

Tugendhat (1998) afirma que "um conceito de moral que não permitiria manter a possibilidade de uma pluralidade de concepções morais é hoje inaceitável" (p. 49). Estará o filósofo defendendo o chamado 'relativismo moral'? Existem dois tipos de relativismo moral, um que podemos chamar de axiológico, outro de antropológico.

$\mathrm{O}$ relativismo axiológico implica pensar que todos e quaisquer valores morais assumidos por diversas culturas ou pessoas (e as regras de conduta decorrentes) equivalem-se, sendo impossível estabelecer uma hierarquia entre eles ou considerar alguns como imorais. Por exemplo, o relativista moral, embora não pratique, ele mesmo, excisão genital em meninas, considerará como válido que algumas pessoas o façam em nome de preceitos religiosos. Em tal relativismo, a tolerância é máxima. $\mathrm{O}$ relativismo moral levanta graves questões, tanto morais quanto psicológicas. Do ponto de vista moral, essa tolerância ilimitada destrói a si mesma. Como escreve Spaemann (1994): “A tolerância não é, de forma alguma, a decorrência natural do relativismo moral, como é frequentemente afirmado. A tolerância tem seu fundamento numa convicção moral bem determinada, uma convicção para a qual exige-se universalidade" (p. 23). Essa mesma universalidade coloca em cheque a possibilidade do relativismo moral do ponto de vista psicológico: como pode alguém, realmente convicto de que mutilar alguém é moralmente errado, aceitar, sem maiores problemas de consciência, que se mutilem pessoas seja lá em que lugar do mundo for? Faltarlhe-ia experimentar o sentimento de indignação, inseparável do sentimento de obrigatoriedade.

O relativismo antropológico é de outra espécie: não consiste em afirmar que todas as opções morais se valem, mas que, de fato existem. Por exemplo, aqui, matar o ímpio é proibido, lá é um dever; aqui, manter relações sexuais fora do casamento é permitido, acolá é terminantemente proibido etc. É nesse sentido que Tugendhat (1998) nos fala em pluralidade de concepções morais. Porém, não acreditamos que ele sugere uma total dispersão dos deveres. Se formos analisar os diversos sistemas morais conhecidos, verificaremos que as virtudes justiça e benevolência estão sempre presentes. Mas o fato é que essa presença recebe interpretações bastante diversas e até contraditórias. Terroristas islâmicos matam em nome da justiça (divina), militantes dos direitos humanos condenam a pena de morte, também em nome da justiça. Em suma, parece que, de fato, o plano moral pode ser ocupado por uma variedade de conteúdos.

Mas tudo ainda não está dito a respeito do relativismo moral antropológico. Os leitores de Piaget e Kohlberg hão de lembrar que para esses dois autores, há um desenvolvimento moral cujo vetor leva a uma determinada moral. Para Piaget (1932), o gênese individual da moralidade parte da anomia, passa pela heteronomia e chega à autonomia. Mas o que é, para Piaget, a moral autônoma? É, entre outras coisas, uma moral da igualdade, da reciprocidade, do respeito mútuo. Logo, se ele tiver razão, o indivíduo moralmente autônomo não poderá legitimar deveres contraditórios com tais critérios. Dito de outra maneira, ao final da gênese da moralidade, o plano moral seria ocupado por uma determinada moral e não qualquer uma. Essa tese foi retomada e sofisticada por Kohlberg (1981). Para ele, o vetor do desenvolvimento moral leva ao ideal de justiça pela equidade, à perspectiva da reciprocidade universal, ao imperativo categórico kantiano que reza que devemos sempre tratar a humanidade, na nossa própria pessoa e na pessoa de outrem, como um fim em si e não apenas como meio. Portanto, tanto em Piaget como em Kohlberg, há a recusa do relativismo moral antropológico, uma vez que o desenvolvimento moral segue, para toda e qualquer pessoa, uma direção precisa. Todavia, é preciso sublinhar que a negação do relativismo moral é 
apenas parcial, e isto por um motivo bem simples: ambos os autores reconhecem que, no caminho para a autonomia ou reciprocidade universal, há os estágios da moral heterônoma, aqueles durante os quais os indivíduos legitimam os valores e normas impostas pela cultura na qual vivem. Portanto, não é contraditório com essa abordagem teórica afirmar que há pluralidade de concepções morais. Seu provir será deixarem o lugar à moral da reciprocidade, mas enquanto isto não acontece (seja no nível do indivíduo, seja no nível da cultura), prevalecem as outras. Aliás, note-se que as pesquisas de Kohlberg mostram que poucos são os indivíduos que chegam ao estágio da moral pós-convencional, a maioria ficando na moral convencional, justamente aquela que pensa a moral como garantia de estabilidade social (e não como inspiração para uma sociedade melhor, como pensam aqueles no estágio ulterior).

Voltemos agora ao que assinalamos acima: nas abordagens de Piaget e Kohlberg, há uma tese psicológica a respeito do conteúdo da moral. Eles não falam de 'qualquer moral' pois pensam que os processos psicológicos de desenvolvimento inevitavelmente trazem ao plano moral deveres inspirados pela reciprocidade. Em compensação, eles pouco ou nada nos dizem no que tange ao aspecto energético da ação. Essa constatação não equivale a uma crítica: o objetivo das investigações desses dois grandes autores foi o de observar e analisar a dimensão racional da moralidade, não sua dimensão afetiva. $\mathrm{O}$ conjunto de dados que tal abordagem construtivista reuniu é considerável e nenhum pesquisador interessado em moral pode, sem mais, descartá-lo e interpretar como quimera a afirmação de que o desenvolvimento da razão tem influência sobre as escolhas de que moral adotar. Todavia, o fato é que esse construtivismo deixa em aberto a dimensão energética, questão esta que pode ser assim formulada: os indivíduos sempre se comportam de maneira coerente com o que julgam ser o moralmente correto? O que está em jogo é a relação juízo/ação, logo a relação saber/querer (a ação moral, como toda ação, pressupõe um querer agir).

Piaget estava consciente desse embate, tanto que redigiu um avertissement à guisa de introdução de seu livro de 1932, no qual, na primeira linha, já avisa o leitor que "é o juízo moral que nos propomos a estudar, e não as condutas ou os sentimentos morais". Kohlberg (1981) sempre também frisou que o desenvolvimento do juízo moral é condição necessária, mas não suficiente para explicar as ações humanas. É claro que ele pressupunha a existência de uma correlação entre nível de desenvolvimento moral e ação morais. Todavia, as pesquisas não confirmaram totalmente tal fenômeno: ele às vezes é observado, outras vezes não (ver Biaggio, 2002; Blasi,1995; Colby \& Damon, 1993). Em suma, a despeito de sua riqueza conceitual, a perspectiva construtivista de Piaget e Kohlberg fica devendo uma explicação para a ação moral que leve em conta a relação entre juízo e volição.

Mas, por que não buscar essa explicação em outras teorias que, justamente, enfrentaram essa questão? Pode-se fazê-lo, é claro, mas não para complementar a abordagem construtivista! Como o assinalamos acima, as teorias que contemplam a dimensão do querer agir moral nos descrevem um sujeito moralmente heterônomo e um plano moral aberto a todo e qualquer sistema moral. É o caso da teoria de Durkheim: é moral o que a sociedade, este 'Ser Coletivo', decidir que é, e a ação moral de cada indivíduo é inspirada por um sentimento do sagrado experimentado por fontes de autoridade. Também é o caso da teoria psicanalítica: é moral o que a sociedade impõe como tal através das figuras parentais, e a ação moral é comandada por uma esfera inconsciente que se instalou na psique humana por um duplo processo de renúncia e repressão. O que há de comum entre Durkheim e Freud é a hipótese de que a moral instala-se em cada indivíduo por um processo de interiorização, uma pressão social (a abordagem behaviorista tem a mesma hipótese) que molda o indivíduo. Ora, essa hipótese é diametralmente oposta àquela construtivista que pressupõe uma atividade criadora do sujeito.

Em resumo, se ficarmos com as teorias psicológicas clássicas da motivação para a ação moral, devemos assumir o relativismo moral e a heteronomia básica de cada indivíduo; e se ficarmos com as teorias do juízo moral, reconhecemos a realidade da autonomia e da progressiva unidade da moral, mas nos privamos de um entendimento do querer agir. Tudo se passa como se o estudo da dimensão afetiva implicasse o relativismo e a heteronomia morais, e aquele da dimensão cognitiva implicasse um ser afetivamente misterioso. Kant (1994) parece ter tido razão ao afirmar o inevitável divórcio entre autonomia moral e sensibilidade.

Porém, não pode ficar paralisado nem intimidado o estudioso da moral convencido da realidade da autonomia moral e da necessidade de identificar as raízes afetivas da ação moral. Talvez possamos achar novas pistas teóricas no campo da ética.

\section{O Plano Ético}

Comumente, as palavras 'moral' e 'ética' são empregadas como sinônimas. Por exemplo, diz-se de uma pessoa que 'ela não tem ética' para criticar seus comportamentos e atitudes; poder-se-ia muito bem chamá-la 'imoral'. Quando se fala em 'problemas éticos', costuma-se fazer referência a questões atinentes aos deveres, portanto, ao plano moral. Em uma palavra, emprega-se, na maioria das vezes, ética como sinônimo de moral. Note-se que tal sinonímia é perfeitamente aceitável do ponto de vista acadêmico, e alguns autores empregam um ou outro conceito indistintamente. Vejamos definições de dicionário para nos convencermos da legitimidade dessa sinonímia. O Dicionário Houaiss (2001), por exemplo, traz como uma das definições de moral "conjunto de regras, preceitos, etc. característicos de um determinado grupo social que os estabelece e defende" (p. 1958). Para a ética, o referido dicionário coloca: "conjunto de regras e preceitos de ordem valorativa e moral de um indivíduo, de um grupo social ou de uma sociedade" (p. 1270). Outros dicionários também atestam a sinonímia. Há de se notar que, hoje em dia, assistimos a uma valorização da palavra 'ética' em detrimento da palavra 'moral'. Eis a avaliação crítica que Spitz (1995) faz dessa preferência: "Esse termo (ética), que tomou uma importância cada vez maior, veio para aliviar o inextricável embaraço daqueles que desejariam falar em moral sem ousar pronunciar esta palavra" (p. 149). Eis um diagnóstico convincente!

Todavia, há possibilidades de estabelecer, por convenção, diferenças entre 'moral' e 'ética'. As duas mais 
frequentes e consagradas mantêm os dois termos como referência a deveres. A primeira dessas possibilidades consiste em reservar a palavra 'ética' a deveres de ordem pública. É o caso de expressões como 'ética da política', 'ética da empresa', 'código de ética' (de determinadas profissões), ou ainda 'comitê de ética para pesquisa com seres humanos'. Está claro que em todos esses exemplos, o que está em jogo é um conjunto de princípios e regras que visam estabelecer obrigações por parte das pessoas contempladas. Ética na política nos remete, entre outros conteúdos, ao preceito da honestidade (não enganar o eleitor, não apoderar-se de bens públicos, não fazer tráfico de influências etc.): tal ética, portanto, exige comportamento moral. Os diversos códigos de ética trazem normas que devem, de maneira obrigatória, reger as atividades dos profissionais, normas cujas raízes encontram-se na moral legitimada pela sociedade. Mesma coisa pode-se dizer da atualmente muito em voga 'ética da empresa': trata-se de normatizar condutas (respeitar o cliente, por exemplo). Finalmente, os comitês de ética na pesquisa com seres humanos visam a regulamentar as atividades de investigação para garantir o bem-estar físico e psicológico dos sujeitos que se submetem a procedimentos de investigação científica. Além de sua referência a deveres, o que há em comum nas expressões analisadas é o fato de referirem-se a ações que dizem respeito ao espaço público (não faria muito sentido em se falar em 'ética familiar').

Uma segunda possibilidade de diferenciar ética de moral é reservar a primeira para os estudos científicos e filosóficos do fenômeno moral. É esta, aliás, a diferenciação mais empregada no meio acadêmico. Kant (1994), um dos primeiros a colocar ordem nos conceitos de moral e ética, propõe que se defina ética como a ciência das leis da liberdade (a física seria a ciência das leis da natureza). Outros autores, como o já citado Tugendhat (1998), definem ética de forma semelhante: reflexão filosófica sobre a moral. Mas, como já dito, a reflexão pode ser de ordem científica, como a busca empírica de dados para explicar o fenômeno moral, como o fizeram autores como Lévy-Bruhl (1971), Durkheim (1974), Freud (1991), Piaget (1932) e tantos outros. Mesmo aceita essa diferença de sentido, verifica-se que se permanece no campo do dever, da obrigatoriedade, portanto, permanece-se no que chamamos de plano moral: apenas o nível de abstração faz a diferença entre os dois termos.

Todavia, há outra possibilidade de diferenciar-se ética de moral, que rompe claramente com a sinonímia. Leiamos a proposta de Paul Ricoeur (1990), a qual faremos nossa: "E por convenção que reservarei o termo ética para a busca (visée) de uma vida realizada (accomplie) e o de moral para a articulação dessa busca com normas caracterizadas ao mesmo tempo pela pretensão à universalidade e por um efeito de coação" (p. 200).

Vemos que Ricoeur (1990) define moral como o fizemos até agora. Todavia, reserva o termo ética para outro plano: o da definição e busca do que seja uma 'vida realizada', ou, em termos filosóficos clássicos, uma 'vida boa' ou 'feliz'. Outros autores contemporâneos fazem distinção semelhante entre moral e ética. Citemos dois, começando por Bernard Williams, que inicia seu livro L'Ethique et les Limites de la Philosophie (1990) afirmando que "o objetivo da filosofia moral e a esperança de que ela possa merecer atenção estão relacionados ao destino dado à questão de Sócrates (de que maneira viver?)" (p. 7). Williams (1990) reserva o conceito de ética para essa ampla questão, e o de moral para os deveres que intimamente nos coagem. Comte-Sponville faz eco aos dois autores citados ao escrever que "a moral responde à questão 'que devo fazer?', e a ética, à questão 'como viver?' (Comte-Sponville, em Comte-Sponville \& Ferry, 1998, p. 214).

Como dito acima, seguiremos os autores que acabamos de citar e diferenciaremos, portanto, o plano ético referente ao tema da 'vida boa' e o plano moral, ao tema dos deveres para com outrem e para consigo mesmo. Falamos em plano ético para diferenciar forma e conteúdo. Com efeito, as respostas ao que seja uma 'vida boa' podem variar, logo, há variadas éticas, como há diversas morais.

Isso posto, devemos lembrar que a questão da vida boa não é nova, que ela preocupa os filósofos desde a antiguidade, e que as respostas dadas costumam responder pelo nome de eudemonismo (teoria da felicidade como bem para o homem). Dizemos que costumam ser chamadas de eudemonismo porque, como apontado por Dupréel (1967), há divergências a respeito de que propostas merecem, de fato, o nome de eudemonismo. Esse autor opta por reservar o referido conceito para as propostas que pressupõem que cada homem sabe muito em que consiste sua felicidade, cabendo à filosofia elaborar as técnicas para conquistá-la. É, por exemplo, o caso do utilitarismo de Mill (1988), para quem a felicidade consiste em "prazer e ausência de dor" (p. 48), e que discute regras de prudência para buscar o prazer e evitar a dor. A outras propostas, que visam a ensinar ao homem o que é a felicidade, Dupréel dá o nome de teorias idealistas. É o caso, por exemplo, de Aristote (1965), cuja ética implica que a felicidade depende da elevação do homem por intermédio do cultivo das virtudes.

Mas deixemos as polêmicas a respeito de que nome merecem os diversos sistemas que se debruçaram sobre a felicidade, pois o que nos interessa aqui é sublinhar o fato de a reflexão sobre a 'vida boa' - seja ela intuitivamente conhecida ou, pelo contrário, revelada pelos sábios - ser tema recorrente da chamada filosofia moral. Aliás, pode-se dizer que esse tema tem sido muito mais trabalhado que o do dever - que somente ganha realce filosófico a partir de Kant, embora tenha sido questão central das religiões de origem judaica ${ }^{2}$. E é grande a variedade e riqueza de temas humanos tratados em nome do que estamos chamando de plano ético: a harmonia do universo e sua relação com o homem, a natureza humana, o papel do conhecimento no alcance da felicidade, as mazelas e virtudes das paixões, o egoísmo e o altruísmo, a convergência social de interesses, a evolução histórica e o porvir do homem etc., e, também, a justiça, a benevolência, a coragem, a fidelidade, ou seja, um conjunto de virtudes que também interessam à reflexão moral.

Podemos, então, dizer que a tese anunciada no início do presente texto - a saber, que para compreendermos os comportamentos morais dos indivíduos precisamos conhecer a perspectiva ética que estes adotam - já foi defendida por

2 Note-se que a moral de Kant propõe deveres coerentes com o 'amor universal' cristão, só que fundamentados na razão e não na fé e obediência a Deus. 
diversos sistemas filosóficos? A resposta a essa pergunta é, cremos, negativa. Seria talvez melhor dizer que é em parte negativa. Expliquemo-lo, lembrando que fizemos uma diferenciação entre moral (conteúdo) e plano moral (forma). É fato que os diversos sistemas que evocam, de uma maneira ou de outra, a questão da 'vida boa', trazem-nos conteúdos morais sob forma de virtudes (justiça, generosidade etc.); porém, eles não as tratam como obrigatórias, mas sim como desejáveis. Ora, o plano moral implica o sentimento de obrigatoriedade. Portanto, se temos no epicurismo, no estoicismo, no utilitarismo, e em outras reflexões éticas, análises precisas de conteúdos morais, falta-nos a articulação entre a busca da felicidade e o dever, ou seja, a articulação entre o que chamamos de plano ético e plano moral. E devemos, sem dúvidas, a Kant o equacionamento preciso das enormes dificuldades de estabelecer tal articulação.

Dos argumentos kantianos podemos lembrar dois, a nosso ver, incontornáveis. O primeiro: a variedade de respostas possíveis ao que seja a felicidade. Escreve Kant (1994): "Embora o conceito de felicidade sirva em todos os casos de base para a relação prática dos objetos da faculdade de desejar, ele é apenas o título geral dos princípios subjetivos de determinação e nada determina especificamente ..." (p. 24). O segundo: a busca da felicidade é determinada pela sensibilidade, logo por algo sobre o qual o homem não tem domínio, em relação ao qual, portanto, é heterônomo. Ora, a responsabilidade moral implica a autonomia. Em suma, para Kant (1990), a moral "é uma ciência que ensina não a maneira pela qual nós devemos nos tornar felizes, mas aquela pela qual devemos nos tornar dignos da felicidade" (p. 15, sublinhado por nós). Essa última definição de moral, rica e precisa, mostra o quanto os planos moral e ético não se articulam facilmente. Todavia, a referência à 'dignidade' fornece-nos uma pista de como estabelecer essa articulação.

Por enquanto, o leitor poderá pensar que, se aceitamos as críticas de Kant a respeito da dificuldade de fazer do eudemonismo uma ciência moral, estamos, a priori, discordando de nossa própria tese segundo a qual os plano moral e ético devem ser pensados conjuntamente para explicarmos os comportamentos morais dos homens. A esse reparo responderíamos o seguinte: se a definição kantiana de dever (imperativo categórico) corresponde a uma realidade psicológica, a referência exclusiva à Razão não explica o fenômeno. Com efeito, vimos que as teorias psicológicas de inspiração kantiana (Piaget e Kohlberg) deixam-nos, teórica e empiricamente, órfãos de uma explicação energética da ação. É, digamos, o seu 'calcanhar de Aquiles'. Aliás, note-se que vários moralistas contemporâneos apontam essa lacuna do sistema kantiano (ver, entre outros, MacIntyre, 1997; Taylor, 1998; Tugendhat, 1998). E vimos também a impossibilidade de articular essas teorias psicológicas racionalistas com aquelas que contemplam as motivações das ações (Durkheim e Freud), pois essas últimas levam ao relativismo moral (variadas podem ser as inspirações do sentimento do sagrado e os mandamentos do superego). Portanto, um mistério psicológico ainda persiste, pelo menos para aqueles que aceitam, com Piaget e Kohlberg, um vetor no desenvolvimento moral e a progressiva conquista da autonomia. É esse mistério que queremos ajudar, se não a desvendar, pelo menos a melhor situar.
Antes de encetarmos essa busca, finalizemos o item dedicado ao plano ético observando duas coisas. A primeira: praticamente nada se encontra em psicologia a respeito do plano ético. Talvez pudesse ser feita uma comparação entre as teorias utilitaristas e a psicanálise, uma vez que ambas as abordagens dão ênfase à importância do prazer e da dor para explicar as ações humanas. Todavia, essa comparação certamente não será fácil porque a hipótese do inconsciente equivale a um verdadeiro abismo separando ambas. A segunda coisa que queremos frisar é o fato de o tema da 'vida boa' ou 'felicidade' ter voltado a ser objeto de publicações recentes. Exemplos: na França, Ferry (2002) acaba de publicar um livro de filosofia intitulado Qu'est-ce qu'une vie réussie?; no Brasil, Giannetti (2002) publicou diálogos sobre a Felicidade; aqui e ali são republicados antigos livros sobre o tema como o de Bertrand Russel (1962), intitulado, em francês, La conquête du bonheur; estão novamente em voga as virtudes, como o atesta o sucesso de venda dos livros de Bennett (1995) e também do Dalai Lama (1999); lembremos também os inúmeros textos de auto-ajuda, cujo triste sucesso reflete um desconforto existencial. Em suma, parece-nos que a inquietação ética está na ordem do dia. A nosso ver é bom que assim seja, pois as reflexões sobre a vida boa são sempre necessárias por incidirem sobre o sentido da vida. Camus (1973), na introdução de seu Mito de Sísifo, afirma que "somente há um problema filosófico realmente sério: o suicídio. Julgar que a vida vale ou não a pena de ser vivida é responder à questão fundamental da filosofia" (p. 15). Interessante lembrar que Camus era um moralista e que, para ele, a busca de sentido para a vida não era estranha às questões morais, como o atesta seu romance L'Etranger.

\section{Moral e Ética: Personalidade Ética}

Aceitas as definições de plano moral e plano ético, a pergunta que imediatamente surge é a de saber se um deles engloba ou determina o outro. Para Comte-Sponville (em Comte-Sponville \& Ferry, 1998), "'a moral está dentro da ética (responder à pergunta 'como viver?' é, entre outras coisas, perguntar-se que lugar reservar aos deveres), bem mais do que a ética está dentro da moral (responder à pergunta 'que devo fazer?', ainda não permite saber como viver e nem mesmo uma vez que a vida não é, aos meus olhos, um dever - se é preciso viver)"' (p. 214) ${ }^{3}$. Ricoeur (1990) apresenta uma posição, por assim dizer, intermediária, ao estabelecer "a primazia da ética sobre a moral, a necessidade para a perspectiva ética de passar pelo crivo da norma (moral), e a legitimidade de um recurso da norma à perspectiva (ética) quando a norma conduz a impasses práticos" (p. 200). Quanto a Tugendhat (1998), "pode-se definir ética diferentemente da moral (ética como busca da 'vida boa'), mas não se pode definir a primeira como algo que englobe a segunda. Isto é impossível.” (p. 32). Como nossa investigação é psicológica, e não filosófica, vamos nos limitar a colocar algumas reflexões sobre a relação axiológica entre os planos moral e ético.

3 Lembremos que para Kant, o suicídio merece ser categoricamente condenado pois equivale a tratar a si próprio como meio, e não como fim: logo, para ele, viver é um dever. 
É claro que a questão ética é mais ampla que a questão moral, mas isso não significa necessariamente que a primeira determine a segunda. Imaginemos, por exemplo, que se opte por definir a 'vida boa' como a busca de poder sobre os homens: não se vê como, de tal busca, podem se deduzir deveres morais. Mais ainda: não serão poucos aqueles que negarão validade a essa opção ética, por achá-la egoísta. É isto que Ricoeur (1990) quer dizer quando fala em passar as opções éticas pelo crivo da norma. Teríamos, portanto, o seguinte quadro: a moral limita a ética. Expressões como 'a liberdade de cada um acaba quando começa a liberdade de outrem', ou 'live and let live', traduzem bem o referido quadro, que poderia ser assim explicitado: cada um é livre para escolher a 'vida boa' que quiser, contanto que reconheça aos outros o mesmo direito e não os trate como instrumento. Nessa formulação, vê-se a moral como critério de limite para as escolhas do plano ético. Para alguns, o limite acima enunciado ainda pode aparecer como demasiadamente amplo, pois deixaria as ações de benevolência totalmente a critério de cada um, e, portanto, não como dever. Pode-se, então, reformular o enunciado: cada um é livre para escolher a 'vida boa' que quiser, contanto que reconheça aos outros o mesmo direito, que não os trate como instrumento e que se preocupe com seu bem-estar. O que importa perceber nas formulações apresentadas é que o limite moral não parece em nada decorrer das opções éticas. Ele teria outro fundamento. Mas que fundamento é esse? Será que ele não é inspirado pela questão ética? Com efeito, por que respeitar os outros? Por que fazer-lhes justiça? Por que preocupar-se com seu bem estar? Não estará implícito que, sem respeito, sem justiça e sem benevolência, a vida é infeliz? Onde está o poder de convencimento da importância da dignidade humana, senão no fato de seu reconhecimento ser condição necessária para uma 'vida boa'? E não estará pressuposto, em Kant, que o 'merecer ser feliz' corresponde a um grau de felicidade superior a outras formas de 'vida boa'? É o que pensa Adam Smith: "Que maior felicidade que aquela de ser amado e saber que merecemos o amor? Que pior castigo do que ser odiado e saber que merecemos esse ódio?" (Smith, 1999, p. 105, grifo nosso). Concordamos com ele, o que nos faz pensar que, do ponto de vista axiológico, há, sim, relações entre o plano ético e o plano moral.

Essa é a nossa convicção, do ponto de vista psicológico. Para começar a apresentá-la, vamos nos debruçar sobre o que realmente pode significar, para o ser humano, a 'vida boa' ou a 'felicidade', termos consagrados em diversos sistemas éticos (não vamos revisitar as concepções da antiguidade, inspiradas em sistemas metafísicos estranhos ao homem moderno).

Gozar de saúde e ter condições mínimas de sobrevivência, certamente, representam o patamar a partir do qual se pode falar em 'vida boa'. Aristote (1965) já o afirmava e o bom senso o confirma. Mas uma vez garantido esse direito universal, o que mais associar ao alcance e usufruto da felicidade? O leque de conteúdos pode ser grande: amar e ser amado, construir uma família, gostar do que se faz no trabalho, reconhecimento social, amigos, possibilidades de lazer, de alimentar-se intelectualmente, ter uma vida sexual ativa e prazerosa etc. Esses itens, e outros possíveis, fazem todo sentido. O problema é que não se identifica, entre eles, um eixo comum. Estamos em plena dispersão. Outro problema é que cada um deles levanta questões complexas quanto à sua definição (por exemplo, o que é a amizade?). Outro problema ainda: é perfeitamente possível pessoas dispensarem um ou outro item (o solitário prefere não ter amigos). Finalmente, observemos que tais itens correspondem mais a 'pedaços de vida', do que à vida como um todo. Ora, como o afirma Williams (1990), "é preciso pensar numa vida inteira" (p. 11) para realmente responder à questão de Sócrates sobre a vida que vale a pena ser vivida. Devemos, portanto, perguntar-nos se há algo em comum por detrás dos diversos conteúdos que podem ocupar o plano ético.

Uma resposta clássica consiste em identificar a busca do prazer e a fuga do desprazer como invariantes do plano ético. Já vimos que os utilitaristas e a psicanálise de Freud encontram-se, nesse ponto, em companhia dos epicuristas. A tese hedonista é simples e elegante. Simples porque identifica no 'princípio do prazer' a motivação básica de todas as ações humanas e elegante justamente em razão dessa simplicidade, que evita a profusão de conceitos articulados em arquiteturas teóricas complexas. Além do mais - e isto é essencial - permite separar claramente forma de conteúdo: todos os hedonistas afirmam a fundamental importância da busca do prazer, mas podem divergir sobre o que é, ou sobre o que deveria ser, esse prazer. Para o psicólogo, essa tese permite explicar comportamentos totalmente diversos. Em poucas palavras, a tese hedonista permite destacar o plano ético (busca do prazer e fuga do desprazer) de diferentes éticas (conteúdos associados ao prazer). Todavia, ela não deixa de apresentar problemas sérios, sendo o principal deles o aparente desmentido dos fatos, como por exemplo, a autodestruição observável em vários indivíduos, que levou Freud a ir 'para além do princípio de prazer' e fazer a hipótese da existência e da força de um instinto de morte. Spaemann (1994) apresenta um argumento diferente para negar a central importância do princípio de prazer e de conservação. Ele nos pede para imaginar a possibilidade de nosso cérebro ser conectado a cabos que conduzem correntes elétricas que nos deixariam em estado constante de euforia, e nos pergunta se estaríamos dispostos a ficar para o todo sempre nessa situação que nos garantiria prazer constante e ausência definitiva de dor. Esse autor afirma que sentiríamos repulsa por uma alternativa de vida desta porque implicaria estarmos "fora da vida efetivamente real, fora da realidade" (p. 34). Conclui o filósofo: "o sentido verdadeiro da vida não reside nem no prazer, nem na conservação" (Spaemann, 1994, p. 36).

Concordamos com o inevitável reducionismo implicado pelas teses hedonistas, embora reconheçamos não ser fácil derrubá-las. Mas há uma coisa nelas que deve ser resgatada: a identificação de algo que esteja presente em todas as opções possíveis de felicidade, ou, melhor dizendo, algo que explica - pelo menos em parte - as escolhas feitas para viver uma 'vida boa'. Acreditamos encontrar esse invariante na noção de sentido da vida.

Acabamos de ver que Spaemann (1994) nega que o prazer e a conservação sejam aquilo que confere sentido à vida. Também vimos acima que Camus (1973) elege o suicídio como grande problema filosófico porque julga que "o sentido da vida é a mais urgente das perguntas" (p. 16). Outros autores, como Taylor (1998), insistem sobre o fato de a atribuição de sentido ser fundamental para se poder 
viver. Para esse autor, 'dar sentido' é "definir o que torna as reações apropriadas: identificar o que torna algo um objeto digno delas e, correlativamente, melhor definir a natureza das reações e explicar tudo que está implicado quanto a nós mesmos e nossa situação no mundo" (p. 22). Mais adiante, escreve que a busca de algo na vida "é sempre busca de sentido" (p. 33)

Certamente, seriam necessárias várias páginas para analisar em profundidade a importância maior do sentido da vida para a realização de uma 'vida boa'. Remetemos o leitor aos autores que citamos, entre eles MacIntyre (1997), que aborda a questão pela dimensão da narrativa, dimensão esta tratada por Ricoeur (1990). Limitemo-nos a dizer que o sentido da vida remete à questão do 'por que viver?' e, logo, a escolhas existenciais que revelem o que é uma vida que vale a pena ser vivida. As opções que colocamos como possíveis conteúdos da 'vida boa' (amor, amizade, reconhecimento social, vida sexual etc.) não são estranhas ao tema do sentido, pois cada uma pode corresponder a um 'existir para'. Para finalizar, lembremos que, no mundo contemporâneo, a angústia frequentemente se traduz pela falta de sentido (ver Taylor, 1998). Como escreve Collin (2003), "a reflexão ética moderna esteve frequentemente confrontada à questão da perda de sentido da vida" (p. 41).

Em resumo, para nós, o invariante do plano ético é a busca de sentido para a vida, e os diversos conteúdos dependerão dos diversos sentidos atribuídos à vida. Já podemos perceber uma relação entre o plano ético e o plano moral: se o grande problema da vida é ela fazer sentido, deduz-se que a moral, ela mesma, e as obrigações dela derivadas, devem também fazer sentido. A questão do sentido é incontornável no plano moral, e certamente não é por acaso que a anomia moral, ou o 'crepúsculo do dever', diagnosticados atualmente, são contemporâneos das dificuldades de encontrar um sentido para a vida e, logo, para as ações.

Mas essa afirmação ainda não é suficiente para se saber que plano determina qual, ou se são independentes. Para defender a hipótese da prevalência do plano ético sobre o plano moral, devemos nos perguntar se há, dentro da própria problemática do sentido da vida, um outro invariante de ordem psicológica. Pensamos que tal invariante existe: o sentimento de 'expansão de si próprio'. Dito de outra forma: fazemos a hipótese de que a possibilidade de 'expansão de si próprio' é condição necessária para que a vida faça sentido, assim como este fazer sentido é condição necessária à 'vida boa'.

Assumimos aqui a perspectiva teórica de Adler (1991), para quem "é unicamente o sentimento de ter atingido um grau satisfatório na tendência a elevar-se que pode fornecer um sentimento de quietude, de valor e de felicidade" ( $p$.

4 Jovens por nós pesquisados parecem the dar certa razão, pois numa investigação junto a 5160 alunos do Ensino Médio da Grande São Paulo (oriundos de escolas particulares e públicas), aos quais foi perguntado se o mais importante para a vida era, (1) ser amado, (2) ser tratado de forma justa, (3) achar que a vida vale a pena ser vivida, a maioria optou pela alternativa 3 (ver La Taille, 2006).

5 Escreve MacIntyre (1997): "Quando alguém se queixa, como os suicidas, que sua vida não tem sentido, ele se queixa talvez de que o relato de sua vida tornou-se, para ele, ininteligível, sem objetivo, sem movimento para um apogeu ou um thelos" (p. 211).
56). A expressão 'expansão de si próprio' não é de autoria de Adler, mas sim de Piaget (1954), que concordava plenamente com o ex-colaborador de Freud, por ver, na tendência à superação de si mesmo, o vetor do desenvolvimento e a motivação central para as ações. Assumimos, portanto, a hipótese de que a vida somente pode fazer sentido para quem experimenta o sentimento de nela autoafirmar-se, expandirse, em uma palavra, atribuir-se valor. Pela recíproca, quem não consegue, seja lá por que motivo for, atribuir a si próprio valor, não consegue dar sentido à sua vida e, logo, não usufrui de uma 'vida boa'.

A tese acima exposta pode ser traduzida com dois outros termos: representações de si e valor. Dedicamos dois livros à análise desses dois conceitos e de sua relação com o sentimento de vergonha, e retemos o leitor a eles para o aprofundamento da questão (La Taille, 2002a, 2006; ver também Harkot-de-La-Taille \& La Taille, 2004). Basta aqui apresentar as ideias básicas.

Entendemos o Eu como um conjunto de representações de si (imagens que a pessoa faz de si). Não importa conferir se tais representações correspondem, de fato, ao que a pessoa realmente é ou a como é vista pelos outros, mas sim sublinhar o fato de que elas correspondem ao que ela julga ser. Importante frisar que colocamos representações de si no plural: não se trata de um autoconceito, portanto unitário, mas realmente de um conjunto de representações, que podem até ser conflitivas ou contraditórias entre si.

Prossigamos: essas representações de si são sempre valor. Definimos valor como investimento afetivo, tal qual Piaget (1954), e assumimos que, inevitavelmente, o Eu é objeto de investimento afetivo. Por isso dizemos que as representações de si são sempre valor. Coerentemente com a teoria de Adler, assumimos também - e isto é essencial para nossa análise - que a busca de representações de si com valor positivo é lei fundamental da vida humana. $\mathrm{O}$ insucesso nessa busca causa o sentimento de vergonha, ou seja, a dor psíquica resultante da consciência da disjunção entre uma 'boa imagem' (idealizada) e a imagem que, de fato, se tem de si (Harkot-de-La-Taille, 1999). A força do sentimento de vergonha - que pode ser letal - atesta a importância, para a vida, de conseguir ver a si próprio como valor positivo.

Como o leitor pode perceber, não hesitamos em colocar, no plano ético, o 'famigerado' amor próprio. Mas não somos os únicos a reconhecer que a ética não pode traduzir-se na negação do sujeito (ver Savater, 2000), e tampouco a moral pode fazê-lo. Basta atentar para o fato de a pergunta do plano ético 'que vida quero viver?' implica outra: 'quem quero ser?'. Portanto, parece-nos não haver possibilidade de se pensar a ética sem contemplar a dimensão da identidade, e esta, sem a busca de atribuição pessoal (e coletiva) de valor.

Estamos agora em condições de defender nossa tese, segundo a qual, para compreender os comportamentos morais dos indivíduos precisamos conhecer a perspectiva ética que eles adotam.

6 A referência à expansão de si próprio não é estranha à filosofia de Nietzsche sobre a 'vontade de potência'. Escreve ele, "O objetivo não é a felicidade, é a sensação de potência" (Nietzsche, 1995, p. 234). 
Comecemos por resumir o que estabelecemos, do ponto de vista psicológico, para o plano ético: a busca de uma vida boa implica a busca de uma vida com sentido, e uma vida que faça sentido deve, necessariamente, contemplar a 'expansão de si próprio'que se traduz pela busca e manutenção de representações de si com valor positivo. Adotamos, por assim dizer, uma teoria geral da motivação das ações humanas. Note-se que não assumimos uma perspectiva reducionista, que equivaleria a negar a presença e importância de outras fontes motivacionais. Queremos apenas afirmar que a busca de sentido, e dentro dela, a expansão de si próprio, constituem condições necessárias (mas não suficientes) das buscas existenciais no plano ético e, portanto, constituemse em motivação incontornável de todas as ações, entre as quais se encontram aquelas inspiradas pelo sentimento de obrigatoriedade, as ações morais (novamente, devemos reafirmar que não negamos a importância e força de outras fontes motivacionais tipicamente morais, como a simpatia - ou empatia - por exemplo).

Nesse ponto, encontramos a teoria de Psicologia Moral que responde pelo nome de moral self, expressão costumeiramente traduzida por 'personalidade moral' ou, conforme preferimos, 'personalidade ética'. Um dos pioneiros dessa teoria, Blasi (1995), afirma que os valores e as regras morais somente têm força motivacional se associados à identidade. Colby e Damon (1993), após realizarem um estudo com pessoas de caráter moral exemplar, chegaram à conclusão de que "quando há uma unidade entre Eu e moralidade, juízo e conduta são diretamente e previsivelmente relacionados e as ações são realizadas com segurança ... Aqueles para os quais a moralidade é central nas suas identidades pessoais devem ser mais fortemente motivados por suas convicções e objetivos" (p. 151). O especialista em educação moral, Puig (1998), tece considerações semelhantes, que também eram as de Piaget, e que se encontram em filósofos. Segundo Flanagan (1996), “é mais que provável que as variações do autoconceito e dos ideais intrapessoais acarretem uma grande diferença no que é notado, nas emoções, na maneira como nos expressamos e agimos, e também na maneira como dirigimos nossas vidas" (p. 309), e, logo, também, na moral. Taylor (1998) afirma que "o Eu e o bem, ou seja, a Eu e a moral, se interpenetram de forma inextricável" (p. 13). Os autores que acabamos de citar, e outros, não se referem à diferenciação entre moral e ética, mas vê-se que suas abordagens são coerentes com o que escrevemos até aqui. Em resumo, encontramos na teoria da personalidade ética um conjunto de dados e conceitos que sustentam a plausibilidade da relação entre planos ético e moral, e a prevalência do primeiro sobre o segundo, na dimensão psicológica.

Para explicitar melhor tal prevalência, voltemos ao tema do 'conflito', deixado em suspenso mais acima. Perguntávamos sobre a frequência do sentimento de obrigatoriedade em cada indivíduo e assumíamos que, para alguns, e em determinadas situações, tal sentimento sofre um 'eclipse': a pessoa age de forma contraditória com os deveres que, em outras situações, inspiram suas ações. Admitindo que esse fenômeno ocorre, ele pode ser explicado pela hierarquia de valores associados às representações de si. Para descrever essa hierarquia, Colby e Damon (1993) empregam metáfo- ras espaciais: 'valores periféricos' e 'valores centrais'7. Os valores periféricos são aqueles que, embora associados às representações de si, têm força menor e, portanto, menos intensidade motivacional do que outros, justamente aqueles chamados de valores centrais. Imaginemos alguém que preze ver a si mesmo como honesto, mas preze mais ainda ver-se como um 'vencedor' na vida - por exemplo, sucesso profissional. Em situações nas quais agir de maneira honesta não implica comprometer o referido sucesso, ele agirá moralmente. Nesse caso, não há conflito. Mas, se houver (por exemplo, deixar de obter algum sucesso se não enganar um concorrente), o dever moral da honestidade poderá sofrer um 'eclipse', pois o investimento afetivo da 'boa imagem' de vencedor é maior que na 'boa imagem' moral. Se pensarmos no sentimento de vergonha, nosso sujeito hipotético sente mais vergonha de ser mal sucedido do que de não ser honesto, pois a razão de viver (o sentido) está mais na glória do que na honra (ver Pitt-Rivers, 1965). Tal forma de pensar permite evitar a classificação binária das pessoas entre morais e imorais. Em suma, são as opções no plano ético que terão decisiva influência sobre a força do sentimento de obrigatoriedade.

E quanto às pessoas que sempre (ou praticamente sempre) optam por seguir os mandamentos da moral, pode-se delas dizer, pela recíproca, que os valores centrais de suas representações de si são justamente aqueles condizentes com a moral, ou eles mesmos morais. Delas se pode dizer que possuem realmente uma personalidade ética. Isso não implica dizer que não passam por conflitos - pelo menos se não forem heróis ou santos -, mas esses costumam ser resolvidos pela força do sentimento de obrigatoriedade moral, pois, para tais pessoas, ser elas mesmas e ser moral é a mesma coisa.

\section{Considerações Finais}

Para finalizar, voltemos à oposição entre as teorias psicológicas que apontam para o potencial de autonomia moral, traduzida pela adesão a morais da reciprocidade e aquelas que ignoram tal potencialidade. Vimos que as primeiras carecem de explicações energéticas, e que aquelas assumidas pelas segundas reforçam a tese da radical heteronomia dos homens e do relativismo moral. Podemos, então, nos perguntar se a relação que estabelecemos entre os planos ético e moral é coerente com a moral autônoma, assim como com a heterônoma. Acreditamos que sim. As opções no plano ético não são dadas para todo o sempre, podem modificar-se, evoluir, assim como, segundo Piaget e Kohlberg, a moral evolui. É bem provável que à moral heterônoma, cujos conteúdos são coercitivamente colocados pela sociedade, correspondam opções éticas também heterônomas (as 'boas imagens' valorizadas pelo grupo - coerente com a fase do 'good boy, good girl ' do estágio 3 estabelecido por Kohlberg), e que à moral autônoma, inspirada pela reciprocidade entre os homens, correspondam outras opções éticas, sentidos da vida que pressuponham maior individualismo (no sentido de não dar valor à pessoas - e a si próprio - em razão do grupo ao qual pertencem), participação

7 Mais uma vez, reencontramos uma ideia de Nietzsche (1995): “o homem é uma pluralidade de forças hierarquizadas" (p. 289). 
nas decisões sociais, identidade cosmopolita e não grupal, o cultivo da reflexão. É apenas uma hipótese, por sinal passível de ser aferida por provas empíricas, como já foi feito por Colby e Damon (1993), em sua investigação sobre pessoas de vida moral exemplar e, mais recentemente, no Brasil, por nós mesmos (La Taille, 2002a, 2002b), por intermédio do estudo da gênese do sentimento de vergonha, por Tognetta e La Taille (2008), que comprovaram a correlação entre personalidade ética e autonomia, por Tardelli (2009), que investigou a relação entre personalidade ética e ações solidárias em adolescentes, por Nogushi e La Taille (2008), que se debruçaram sobre o universo moral de jovens infratores internado na antiga Febem, e por Dias (2010), cuja tese de doutorado foi dedicada à relação entre personalidade ética e atitudes morais na vida escolar.

Em suma, cremos que pensar a motivação moral por intermédio das opções éticas permite maior flexibilidade para dar conta da variedade de condutas que se observam. Sendo a área da psicologia como é, com profusão de teorias e dos chamados 'novos paradigmas', é difícil saber se a abordagem teórica que responde pelo nome de moral self ou personalidade ética dominará doravante os estudos de Psicologia Moral e Psicologia do Desenvolvimento Moral. Mas, uma coisa é certa, como o explicitamos com referências bibliográficas tanto na filosofia quanto na psicologia: tal abordagem encontra-se fortalecida e inspiradora de novas investigações, Brasil incluído.

\section{Referências}

Adler, A. (1991). Le sens de la vie. Paris: Payot.

Aristote (1965). Ethique de Nicomade. Paris: Flamarion.

Bennet, W. J. (1995). O livro das virtudes. Rio de Janeiro: Nova Fronteira.

Biaggio, A. (2002). Lawrence Kohlberg: ética e educação moral. São Paulo: Moderna.

Blasi, A. (1995). Moral understanding and the moral personality: The process of moral integration. Em Kurtines, D. (Org.), Moral development: An introduction (pp. 229-254). London: Allyn and Bacon.

Camus, A. (1973). Le mythe de Sisyphe. Paris: Gallimard.

Carone, I. (2003). A Psicologia tem paradigmas? São Paulo: Casa do Psicólogo.

Colby, A., \& Damon, W. (1993). The uniting of self and morality in the development of extraordinary moral. Commitment. Em G. G. Noam \& E. Wren (Orgs.), The moral self (pp. 149-174). Cambridge: MIT.

Collin, D. (2003). Questions de morale. Paris: Armand Colin.

Comte-Sponville, A., \& Ferry, L. (1998). La sagesse des modernes. Paris: Lafont.

Dalai Lama (1999). Uma ética para o novo milênio. Rio de Janeiro: Sextante.

Deleuze, G. (2004). L'abécédaire de Gilles Deleuze. Paris: Editions Monparnasse.

Dias, A. F. (2010). Territórios da personalidade ética: ações morais, valores e virtudes na escola. Tese de Doutorado, Universidade de São Paulo, São Paulo.

Dupréel, E. (1967). Traité de morale, Tome 1. Bruxelles: Pressnes Universitaires de Bruxelles.

8 Para uma crítica do emprego do conceito de 'paradigma' na Psicologia, aconselhamos a leitura de Carone (2003).
Durkheim, E. (1974). L'education morale. Paris: PUF.

Flanagan, O. (1996). Psychologie morale et éthique. Paris: PUF. Ferry, L. (2002). Qu'est-ce que réussir sa vie? Paris: Grasset. Freud, S. (1971). Malaise dans la civilisation. Paris: PUF.

Freud, S. (1991). Le moi et le ça. Paris: PUF.

Giannetti, E. (2002). Felicidade. São Paulo: Companhia das Letras.

Harkot-de-La-Taille, E. (1999). Ensaio semiótico sobre a vergonha. São Paulo: Humanitas.

Harkot-de-La-Taille, E., \& La Taille, Y. de (2004). A construção ética e moral de si mesmo. Em M. T. C. de Souza (Org.), Os sentidos de construção: o si mesmo e o mundo (pp. 69-102). São Paulo: Casa do Psicólogo.

Huntington, S. (1999). Le choc des civilisations. Paris: Editions Odile Jacob.

Kant, E. (1994). Métaphysique des moeurs, première partie. Paris: Flamarion.

Kohlberg, L. (1981). Essays on moral development. San Francisco: Harper \& Row.

La Taille, Y. de (2002a). Vergonha, a ferida moral. Petrópolis: Vozes.

La Taille, Y. de (2002b). O sentimento de vergonha e suas relações com a moralidade. Psicologia: Reflexão e Crítica, , 15, 13-25.

La Taille, Y. de (2006). Moral e ética: dimensões intelectuais e afetivas. Porto Alegre: Artmed.

Levi-Bruhl, L. (1971). La morale et la science des moeurs. Paris: PUF.

Lipovetsky, G. (1992). Le crépuscule du devoir. Paris: Gallimard. MacIntyre, A. (1997). Après la vertu. Paris: PUF.

Mill, J. S. (1988). L'utilitarisme. Paris: Flamarion.

Nietzsche (1995). La volonté de puissance I. Paris: Gallimard.

Nogushi N., \& La Taille, Y. de (2008). Universo moral de jovens internos da Febem. Cadernos de Pesquisa, 38, 11-40.

Piaget, J. (1932). Le jugement moral chez l'enfant. Paris: PUF.

Piaget, J. (1954). Les relations entre l'affectivité et l'intelligence.

Paris: Sorbonne.

Piaget, J. (1977). Etudes sociologiques. Paris: Droz.

Pitt-Rivers, J. (1965). Honra e posição social. Em J. G. Peristiany (Org.), Honra e vergonha (pp. 11-60). Lisboa: Fundação Capouste Gulbenkian.

Puig, J. M. R. (1998). A construção da personalidade moral. São Paulo: Ática.

Ricoeur, P. (1990). Soi-même comme un autre. Paris: Gallimard. Russell, B. (1962). La conquête du bonheur. Paris: Payot.

Savater, F. (2000). Ética como amor-próprio. São Paul: Martins Fontes.

Spitz, B. (1995). La morale à zéro. Paris: Seuil.

Smith, A. (1999). Théorie des sentiments moraux. Paris: PUF. Spaemann, R. (1994). Notions fondamentales de morale. Paris: Flammarion.

Tardelii, D. D. (2009). Adolescência, personalidade e projeto de vida solidário. Em Y. de La Taille \& M. S. de S. Menin (Orgs.), Crise de valores ou valores em crise (pp. 70-88). Porto Alegre: Artmed .

Taylor, C. (1998). Les sources du moi. Paris: Seuil.

Tognetta, L R. P., \& La Taille, Y. de (2008). A formação de personalidades éticas, representações de si e moral. Psicologia: Teoria e Pesquisa, 24, 181-188.

Tugendhat, E. (1998). Conférences sur l'éthique. Paris: PUF.

Williams, B. (1990). l'Ethique et les limites de la philosophie. Paris: Gallimard. 